\title{
PURWARUPA SISTEM PENGAMBILAN DAN PENGOLAHAN DATA KANDUNGAN GAS KARBON MONOKSIDA DI UDARA MENGGUNAKAN RASPBERRY DAN SENSOR MQ-7
}

\author{
Rizky Kurnia Aziz Musthofa' ${ }^{1}$ Kasyful Amron², Wijaya Kurniawan ${ }^{3}$ \\ ${ }^{1,2,3}$ Fakultas Ilmu Komputer Universitas Brawijaya \\ Email: 1er.musthofa@gmail.com, ${ }^{2}$ kasyful@ub.ac.id, ${ }^{3}$ wjaykurnia@ub.ac.id \\ (Naskah masuk: 30 Januari 2017, diterima untuk diterbitkan: 28 Februari 2017)
}

\begin{abstract}
Abstrak
Proses pengambilan data terkait dengan kondisi lingkungan pada area yang luas biasanya dilakukan secara manual dengan melibatkan banyak pihak terkait. Termasuk didalamnya tapi tidak terbatas pada personal, perangkat pendukung dan waktu. Semakin banyak data yang diambil, maka semakin banyak sumber daya yang dibutuhkan. Penelitian ini mencoba untuk membuat purwarupa perangkat yang dapat menjadi alternative prosedur atau proses pengambilan data dengan memanfaatkan komputer nano raspberry dan sensor serta modem sebagai perangkatnya. Sensor yang digunakan adalah sensor MQ-7. Sensor ini berfungsi untuk mengukur kadar kandungan zat karbon monoksida di udara. Karena itu, purwarupa ini mampu mengukur dan mengolah informasi kadar gas karbon monoksida di area tertentu. Sebagai tambahan fitur, data dari purwarupa ini kemudian dapat dilihat oleh pengguna melalui antarmuka web.
\end{abstract}

Kata kunci: raspberry pi, sensor $M Q-7$, web services

\section{Abstract}

The processes of data retrieval for such a large areas, such as plantations or industrial area, are often done manually and directly that involving a lot of resources. Including but not limited to personal, supported devices, and time. As more data is taken, the more resources are needed. This research tries to make a prototype device that can help in data sampling processes and at the same time visualize the data digitally and directly utilizing nano computer Raspberry Pi as the primary device and is equipped with MQ-7sensors to capture and measure carbon monoxide from the air and modems as the communication enhancement. While the GSM Card and GPRS modem are added and used to transmit data from sensor to computer server computer that will perform the data processing and visualization with a web-based applications. This prototype shows that the system is able to measure and process the information content of carbon monoxide actual and visible to users through a web interface after being processed by the server.

Keywords: raspberry pi, sensor MQ-7,GPRS, realtime, web services

\section{PENDAHULUAN}

Oksigen dan beberapa unsur lain di dalam udara adalah unsur penting bagi kehidupan. Namun kadang udara yang tersedia telah banyak tercemar oleh berbagai macam polutan dari berbagai aktifitas yang menghasilkan polusi. Polusi udara dapat dihasilkan dari berbagai sebab diantaranya adalah reaksi kimia dari limbah yang ada di bumi, hasil gas buang kendaraan bermotor, gunung meletus, sisa pembakaran yang ada pada pabrik dan industri serta kebakaran hutan. Dengan melihat data dari berbagai lembaga yang melakukan pengambilan contoh udara, dapat diketahui bahwa terdapat kecenderungan polusi udara senantiasa meningkat setiap tahun. Polusi udara terbesar berasal dari industri dan gas buang kendaraan bermotor. Dampak yang ditimbulkan akibat kandungan polusi dalam jumlah yang melebihi ambang batas yang telah ditentukan akan menyebabkan kualitas udara menurun.
Gas Karbon Monoksida (CO) adalah salah satu dari berbagai jenis gas polutan yang dapat mengakibatkan kualitas udara menurun bahkan cenderung menjadi racun. Karena gas CO tanpa warna, bau dan rasa, sangat sulit untuk mendeteksi keberadaan gas CO di lingkungan. Bah-kan pada tingkat yang relatif rendah, gas $\mathrm{CO}$ dapat meracuni manusia dengan cara menghambat ke-mampuan darah untuk menyalurkan Oksigen $(\mathrm{O} 2)$.

Oleh karena itu pemantauan terhadap gas $\mathrm{CO}$ perlu dilakukan. Dalam rangka mengurangi resiko saat dilakukannya pengamatan, maka diperlukan sebuah sistem yang dapat memantau atau memonitoring peningkatan gas $\mathrm{CO}$ tanpa melibatkan peran serta manusia. Menurut Gheyb Jhuana Ohara dalam "Aplikasi Sistem Monitoring Berbasis Web Untuk Open Cluster", dinyatakan bahwa sistem monitoring merupakan suatu proses untuk mengumpulkan data secara real-time yang terbagi dalam tiga proses besar, yaitu proses pengumpulan data, proses analisis, dan proses menampilkan data hasil monitoring [1]. 
Di dalam proses pengumpulan data menggunakan Embedded System, yang merupakan suatu sistem berbasiskan mikrokontroler yang dibangun untuk mengontrol fungsi atau berbagai fungsi. Embedded System yang digunakan dalam proses ini adalah Raspberry $\mathrm{Pi}$, yang berfungsi sebagai pengontrol sensor dan GPRS modem. Dengan menggunakan Raspberry Pi, Embedded System ini memiliki kelebihan untuk dapat dikontrol dari jarak jauh. Informasi yang diperoleh dari proses pengumpulan data monitoring pada Embedded System akan dikirimkan melalui GPRS modem ke sebuah server. Hasil penerimaan dan pengolahan data akan ditampilkan ke dalam aplikasi web dengan fitur pemantauan kadar gas CO secara real-time dan record kadar $\mathrm{CO}$ pada suatu wilayah.

Dengan dibuatnya Sistem Monitoring Gas Karbon Monoksida Menggunakan Embedded System Raspberry Pi dan Sensor MQ-7 oleh penulis diharapkan dapat membantu memberikan informasi secara real-time tentang tingkat kadar gas $\mathrm{CO}$ pada suatu daerah tertentu sehingga dapat di-lakukan tindakan yang diperlukan oleh pihak-pihak terkait.

\section{PERMASALAHAN}

Berdasarkan uraian latar belakang di atas, maka pada penulisan ini rumusan masalah difokuskan pada bagaimana merancang sistem yang dapat mendeteksi gas karbon monoksida (CO) untuk proses pengumpulan data, bagaimana merancang sistem pengiriman data untuk mengirimkan informasi hasil proses pengumpulan data monitoring ke server, dan bagaimana merancang dan mengimplementasi sistem informasi kadar gas karbon monoksida (CO) berbasis web.

\section{TINJAUAN PUSTAKA}

\subsection{Kajian Pustaka}

Salah satu kajian pustaka yang digunakan sebagai acuan penelitian pada tulisan ini adalah tulisan Marimbun Sibarani dengan berjudul "Implementasi Sistem Wireless Sensor Network Berbasis Internet Protocol (IP) untuk Pemantauan Tingkat Polusi Udara". Pada penelitian ini dinyatakan Wireless Sensor Network dapat berfungsi sebagai sistem monitoring yang memberikan informasi terkait dengan kondisi fisik atau kondisi lingkungan lainnya dari sebuah lokasi. Dalam hal ini sensor dapat memberikan data dari hasil pembacaan secara real-time [2].

Kajian pustaka lain yang juga dipertimbangkan adalah penelitian Bhuvaneswari S. yang berjudul "Implementation of TCP/IP on Embedded Webserver Using Raspberry Pi In Industrial Application". Pada penelitian ini didapatkan bahwa implementasi dari web server menggunakan Raspberry Pi untuk monitoring merupakan metode baru untuk memonitor lingkungan yang di desain secara real-time. Sistem ini mendukung onlinesupervision dan untuk mengontrolnya tidak hanya dapat dilakukan dalam jaringan lokal (LAN) tetapi juga pada jaringan publik (Internet). Keseluruhan sistem memiliki biaya yang rendah, keterbukaan yang baik dan portabilitas, dan mudah untuk dimaintain dan di-upgrade. Pada sistem ini juga memungkinkan untuk menambahkan beberapa macam modul sensor yang berbeda dan membuat beberapa aplikasi yang berbeda pula. Sehingga sistem ini bisa memonitor operasional embedded system melalui internet, dan mencapai tujuan monitoring melalui jaringan [3].

Kajian pustaka selanjutnya adalah penelitian sebelumnya (Christos Xenakis dan Lazaros Merakos: 2002) yang berjudul "On Demand Network-wide VPN Deployment in GPRS". Pada penelitian ini membahas tentang pengajuan peningkatan layanan keamanan untuk semua pengguna mobile. Skema keamanan yang ditawarkan adalah dengan menempatkan Virtual Private Network (VPN) di atas General Packet Radio Service (GPRS). Skema keamanan yang ditawarkan mampu meningkatkan perlindungan yang sudah didukung pada GPRS. Penelitian ini mampu mengamankan transmisi data pada seluruh rute jaringan dari pengguna mobile menuju remote server dengan memanfaatkan ciphering bawaan GPRS, dan dengan menempatkan IP VPN diatas inti GPRS [4].

Berdasarkan kajian pustaka diatas, penulis ingin melakukan penelitian Sistem Monitoring Tingkat Polusi Udara Menggunakan Embedded System Raspberry Pi dan Sensor MQ-7 yang mengimplementasikan Raspberry Pi sebagai mikrokontroller agar dapat dikendalikan dari jarak jauh dan komunikasi nirkabel dengan menggunakan GPRS modem agar memiliki jangkauan yang lebih luas.

\subsection{Dasar Teori}

\section{Tinjauan Umum Sistem Monitoring}

Sistem monitoring real-time dapat dibedakan menjadi dua sistem berbeda yaitu hard real-time dan soft real-time [5]. Sistem hard real-time ini harus memiliki kemampuan untuk menghasilkan luaran yang tepat pada waktunya, jika hal ini tidak terpenuhi maka akan mengakibatkan sesuatu yang fatal. Sistem hard real-time ini sering digunakan pada embedded system untuk kontrol suatu perangkat, sebagai contoh pada sistem monitoring kapasitas bahan bakar. Sedangkan sistem soft realtime masih memberikan toleransi terhadap suatu keterlambatan apabila dalam rentang waktu tertentu tidak terselesaikan dengan benar. Contoh aplikasi yang termasuk dalam kategori soft real-time ini adalah aplikasi berbasis multimedia. 


\section{Sensor Gas MQ-7}

Sensor MQ-7 merupakan sensor semikonduktor yang terbuat dari material tin oksida $\left(\mathrm{SnO}_{2}\right)$ yang peka terhadap gas CO. Daya konduksi sensor akan semakin tinggi sebanding dengan peningkatan kadar gas CO yang ada di sekitarnya. Berikut adalah grafik karakteristik sensitivitas sensor MQ-7.

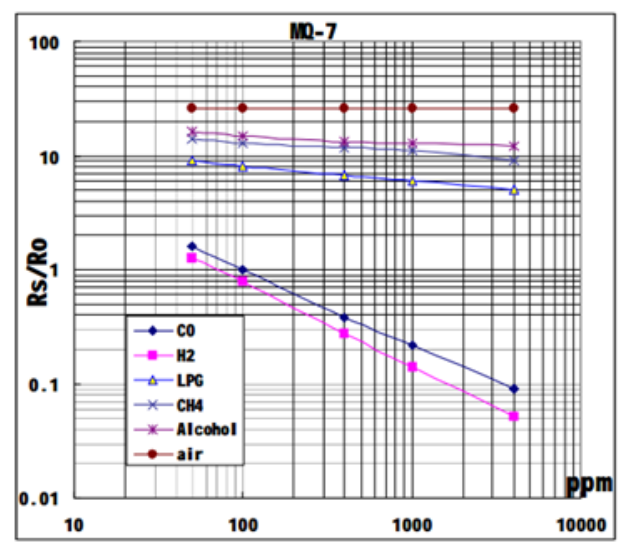

Gambar 1. Karakteristik Sensifitas MQ-7

\section{DT-Sense Gas Sensor}

DT-Sense Gas Sensor adalah modul sensor dengan rangkaian analog to digital converter (ADC) dan soket yang kompatibel dengan sensor MQ-7. Beberapa fitur penting yang ada pada DT-Sense Gas Sensor yaitu:

a. Memiliki kompatibilitas dengan berbagai varian sensor seperti MQ-3, MQ-4, MQ-6, MQ-7, MQ-135, dan MG-811.

b. Dilengkapi rangkain ADC dengan resolusi hingga 10 bit.

c. Dilengkapi antarmuka UART, TTL, dan I2C.

d. Tegangan kerja (Vc) sebesar 5 volt.

\section{Inter Integrated Circuit (I2C)}

Merupakan standar komunikasi serial dua arah dengan menggunakan dua jalur yang didesain khusus untuk berkomunikasi antar perangkat. Sistem I2C terdiri dari jalur Serial Clock (SCL) dan Serial Data (SDA). SCL merupakan jalur yang berfungsi untuk menyalurkan clock yang hanya dapat diaktifkan oleh master agar data yang ditransferkan tetap tersinkronisasi. Sedangkan jalur SDA merupakan jalur yang berfungsi untuk menyalurkan informasi data antara master dengan slave.

\section{DT-I/O Level Converter}

DT-IO Level Converter merupakan rangkaian pengkonversi tegangan yang berfungsi untuk mengkonversi tegangan lima volt menjadi 3.3 volt dan sebaliknya.

\section{Raspberry Pi}

Raspberry Pi merupakan perangkat elektronik dengan ukuran yang tidak jauh berbeda dari ukuran kartu kredit [6]. Perangkat ini terdiri dari berbagai macam komponen elektronik yang disusun di atas Printed Circuit Board (PCB) tanpa memiliki pelindung maupun penutup. Terlepas dari penampilannya, Raspberry Pi memiliki fungsionalitas yang sama seperti komputer pada umumnya. Selain itu Raspberry Pi juga menyediakan jalur I2C pada pin General Purpose Input Output (GPIO) yang akan digunakan dalam penelitian ini.

\section{Socket}

Socket adalah sebuah abstraksi di mana aplikasi dapat mengirim dan menerima data. Socket memungkinkan aplikasi untuk terhubung secara langsung ke dalam sebuah jaringan dan berkomunikasi dengan aplikasi lain yang juga terhubung pada jaringan yang sama. Informasi yang dituliskan sebuah aplikasi terhadap socket pada suatu mesin dapat dibaca oleh aplikasi yang berada pada mesin berbeda.

\section{PEMBAHASAN SISTEM}

Sistem Monitoring Gas Karbon Monoksida (CO) Menggunakan Emberdded System Raspberry Pi dan Sensor MQ-7 memiliki fasilitas sistem pemantauan konsentrasi kadar gas CO menggunakan teknologi GPRS modem dan VPN sehingga dapat memaksimalkan fungsi Raspberry Pi agar dapat dikontrol dari jarak jauh yang dapat memberikan kemudahan dalam proses update maupun upgrade. Selain itu, sistem ini juga menyediakan antarmuka web yang dapat dimanfaatkan untuk memantau konsentrasi kadar gas $\mathrm{CO}$ secara remote selama pengguna menginginkannya.

Sistem monitoring yang dirancang berupa sistem informasi yang menampilkan kadar gas $\mathrm{CO}$ secara aktual setiap 60 detik sekali.

Gambaran sistem secara umum terlihat seperti pada Gambar 2.

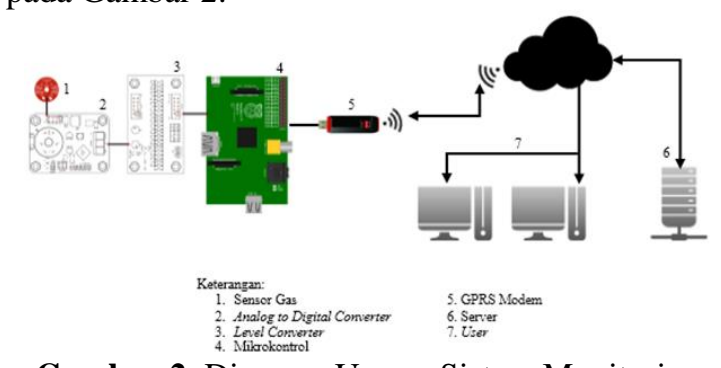

Gambar 2. Diagram Umum Sistem Monitoring

Dari hasil deteksi gas CO oleh sensor MQ-7 perlu dilakukan beberapa langkah untuk mendapatkan nilai parts per million (ppm). Hasil yang diterima oleh mikrokontrol merupakan hasil konversi analog to digital. Untuk mendapatkan nilai 
tegangan keluaran (VRL) sensor MQ-7 dapat dilakukan dengan menggunakan Persamaan 4.1.

$$
V R L=\frac{A D C * V C}{\text { resolusi } A D C-1}
$$

Langkah berikutnya adalah menghitung nilai resistansi sensor (Rs) dengan menggunakan nilai VRL. Dan resistansi sensor pada 100 ppm CO (Ro) dengan menggunakan Persamaan 4.2.

$$
R s=\frac{V c-V R L}{V R L} \times R L
$$

RL adalah resistansi variabel yang disediakan oleh ADC sebesar $3 \mathrm{~K} 3 \Omega$.

Ro merupakan resistansi sensor pada 100 ppm CO. Nilai Ro yang didapat dalam penelitian ini adalah 28430.76 .

Dengan diketahuinya nilai Rs dan Ro maka dapat dilakukan konversi nilai kadar gas CO dalam satuan ppm. Rumus untuk mencari nilai ppm diperoleh dari hasil pembuatan kembali grafik karakteristik sensitifitas sensor MQ-7 dari persamaan power dengan menggunakan analisis trendline seperti pada Persamaan 4.3.

$$
p p m=102.57\left(\frac{R s}{R o}\right)^{-1.519}
$$

Dengan menggunakan Persamaan 4.3 ini kadar gas CO dalam satuan ppm dapat dicari.

\section{HASIL DAN PEMBAHASAN}

\section{Pengujian dan Analisis Sistem Deteksi Gas}

Tabel 2. Hasil Konversi Dalam Satuan CO

\begin{tabular}{|c|c|c|c|c|c|}
\hline $\begin{array}{c}\text { N } \\
\text { o. }\end{array}$ & $\begin{array}{c}\text { Hasil } \\
\text { Prgm }\end{array}$ & $\begin{array}{c}\text { Grafik } \\
\text { Karakte } \\
\text { ristik }\end{array}$ & $\begin{array}{c}\text { N } \\
\text { o. }\end{array}$ & $\begin{array}{c}\text { Hasil } \\
\text { Prgm }\end{array}$ & $\begin{array}{c}\text { Grafik } \\
\text { Karakte } \\
\text { ristik }\end{array}$ \\
\hline 1 & 50 & 54 & 16 & 37 & 41 \\
\hline 2 & 46 & 49 & 17 & 58 & 61 \\
\hline 3 & 43 & 47 & 18 & 55 & 58 \\
\hline 4 & 43 & 47 & 19 & 46 & 49 \\
\hline 5 & 39 & 43 & 20 & 48 & 51 \\
\hline 6 & 39 & 43 & 21 & 124 & 134 \\
\hline 7 & 37 & 41 & 22 & 80 & 84 \\
\hline 8 & 37 & 41 & 23 & 63 & 67 \\
\hline 9 & 37 & 41 & 24 & 66 & 69 \\
\hline 10 & 37 & 41 & 25 & 48 & 51 \\
\hline 11 & 37 & 41 & 26 & 60 & 63 \\
\hline 12 & 34 & 38 & 27 & 48 & 51 \\
\hline 13 & 34 & 38 & 28 & 58 & 61 \\
\hline 14 & 34 & 38 & 29 & 48 & 51 \\
\hline 15 & 34 & 38 & 30 & 46 & 49 \\
\hline
\end{tabular}

Sumber: [Hasil dan Pembahasan]

Pengujian sistem deteksi gas dilakukan dengan meletakkan perangkat sensor pada ruang terbuka dan kemudian mengaktifkannya. Saat perangkat sensor sudah memasuki kondisi yang stabil untuk membaca kadar gas CO, langkah selanjutnya adalah menjalankan program yang ada pada Raspberry Pi dengan tujuan untuk mengambil hasil baca ADC.
Prosedur pengujian sistem deteksi gas dijalankan selama 30 menit. 15 menit pertama dilakukan pada kondisi udara yang belum diberi gas polutan, dan 15 menit berikutanya dilakukan pada kondisi udara yang diberi polutan. Data tersebut kemudian dikonversi dalam satuan ppm dengan menggunakan Persamaan 4.1, Persamaan 4.2, dan Persamaan 4.3. Tabel 2 menunjukkan hasil konversi dalam satuan ppm.

Berikut perbandingan grafik karakteristik dengan hasil penelitian.

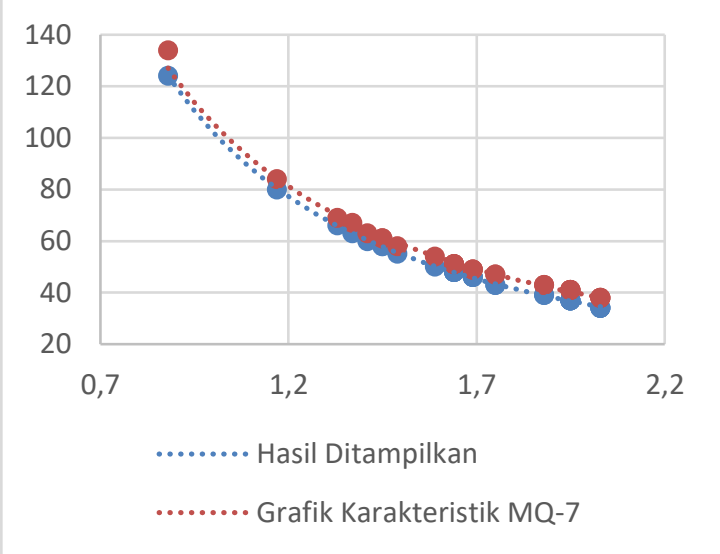

Gambar 7. Grafik Perbandingan Hasil Penelitian

Berdasarkan grafik pada Gambar 7 terlihat bahwa ketiga hasil konversi dalam satuan ppm memiliki pola yang sama tetapi memiliki perbedaan dalam nilai yang disajikan. Hal ini disebabkan karena nilai $R_{O}$ yang digunakan dalam program menggunakan asumsi kalibrasi pada lingkungan yang memiliki kadar 100 ppm CO.

Dari data yang didapatkan, secara umum menunjukkan bahwa sistem deteksi gas masih belum dapat memberikan kadar gas CO secara akurat, namun sistem ini sudah mampu mendeteksi perubahan kadar gas $\mathrm{CO}$ yang ada disekitarnya. Hal ini dibuktikan dengan adanya peningkatan kadar gas CO saat dilakukan pengambilan sampel dalam keadaan udara yang diberi polutan.

\section{Pengujian dan Analisis Sistem Pengiriman Data}

Pengujian sistem pengiriman data dilakukan dengan menjalankan aplikasi penerima data yang ada pada server dan menjalankan aplikasi pengirim data yang ada pada Raspberry Pi. Aplikasi yang ada pada Raspberry Pi akan menampilkan kapan data tersebut dikirim, sendangkan aplikasi yang ada pada server akan menampilkan kapan data diterima. Dengan begitu dapat diketahui besarnya waktu proses pengiriman data dari Raspberry Pi ke server melalui GPRS modem Prosedur pengujian pengiriman data dilakukan setiap 60 detik selama 30 menit. Tabel 3 menunjukkan hasil pengujian sistem pengiriman data. 
Tabel 3. Hasil Pengujian Sistem Pengiriman Data

\begin{tabular}{|c|c|c|c|}
\hline No. & Data Dikirim & Data Diterima & $\begin{array}{c}\text { Selisih } \\
\text { Waktu }\end{array}$ \\
\hline 1 & $16: 20: 29$ & $16: 20: 29$ & 0 \\
\hline 2 & $16: 21: 29$ & $16: 21: 29$ & 0 \\
\hline 3 & $16: 22: 29$ & $16: 22: 29$ & 0 \\
\hline 4 & $16: 23: 29$ & $16: 23: 29$ & 0 \\
\hline 5 & $16: 24: 29$ & $16: 24: 29$ & 0 \\
\hline 6 & $16: 25: 29$ & $16: 25: 29$ & 0 \\
\hline 7 & $16: 26: 29$ & $16: 26: 29$ & 0 \\
\hline 8 & $16: 27: 29$ & $16: 27: 29$ & 0 \\
\hline 9 & $16: 28: 29$ & $16: 28: 29$ & 0 \\
\hline 10 & $16: 29: 29$ & $16: 29: 30$ & 1 \\
\hline 11 & $16: 30: 30$ & $16: 30: 30$ & 0 \\
\hline 12 & $16: 31: 30$ & $16: 31: 30$ & 0 \\
\hline 13 & $16: 32: 30$ & $16: 32: 30$ & 0 \\
\hline 14 & $16: 33: 30$ & $16: 33: 30$ & 0 \\
\hline 15 & $16: 34: 30$ & $16: 34: 30$ & 0 \\
\hline 16 & $16: 35: 30$ & $16: 35: 30$ & 0 \\
\hline 17 & $16: 36: 30$ & $16: 36: 30$ & 0 \\
\hline 18 & $16: 37: 30$ & $16: 37: 30$ & 0 \\
\hline 19 & $16: 38: 30$ & $16: 38: 30$ & 0 \\
\hline 20 & $16: 39: 30$ & $16: 39: 31$ & 1 \\
\hline 21 & $16: 40: 31$ & $16: 40: 31$ & 0 \\
\hline 22 & $16: 41: 31$ & $16: 41: 31$ & 0 \\
\hline 23 & $16: 42: 31$ & $16: 42: 31$ & 0 \\
\hline 24 & $16: 43: 31$ & $16: 43: 31$ & 0 \\
\hline 25 & $16: 44: 31$ & $16: 44: 31$ & 0 \\
\hline 26 & $16: 45: 31$ & $16: 45: 31$ & 0 \\
\hline 27 & $16: 46: 31$ & $16: 46: 31$ & 0 \\
\hline 28 & $16: 47: 31$ & $16: 47: 32$ & 1 \\
\hline 29 & $16: 48: 31$ & $16: 48: 32$ & 1 \\
\hline 30 & $16: 49: 32$ & $16: 49: 32$ & 0 \\
\hline & Rata-rata waktu pengiriman & 0.13 \\
\hline & Sumber: [Hasil dan Pembahasan] \\
\hline
\end{tabular}

Pada hasil pengujian pengiriman data yang dapat dilihat pada Tabel 3 terlihat bahwa dalam proses pengiriman data yang dilakukan oleh mikrokontrol hingga diterima oleh server membutuhkan waktu yang relatif kecil. Hal ini dapat dibuktikan dengan membandingkan waktu pengiriman dengan waktu penerimaan. Rata-rata waktu pengiriman sebesar 0.18 detik. Waktu terbesar yang diperlukan dalam proses pengiriman sebesar 1 detik, dan waktu terkecil dalam proses pengiriman sebesar 0 detik.

\section{Pengujian dan Analisis Sistem Visualisasi Data}

Pengujian sistem visualisasi data dilakukan dengan melihat kesesuaian informasi yang ditampilkan pada antarmuka web dengan data yang dikirimkan oleh Raspberry Pi. Kadar gas CO yang digunakan akan disajikan pada tabel berikut. Tabel 4, data ini akan ditampilkan dalam bentuk grafik sehingga dapat dibandingkan secara visual dengan antarmuka web yang menyajikan kadar gas CO. Berikut merupakan gambar perbandingan antara grafik data yang dikirim dengan grafik sistem visualisasi data.

Data pada Tabel 4 kemudian akan ditam-pilkan dalam bentuk grafik sehingga dapat diban-dingkan secara visual dengan antarmuka web yang menyajikan kadar gas CO. Berikut merupakan perbandingan antara grafik data yang dikirim dengan grafik sistem visualisasi data.

Tabel 4. Informasi Kadar Gas CO

\begin{tabular}{|c|c|c|c|c|c|}
\hline & Jam & CO & & Jam & CO \\
\hline 1 & $16: 20$ & 50 & 16 & $16: 35$ & 37 \\
\hline 2 & $16: 21$ & 39 & 17 & $16: 36$ & 34 \\
\hline 3 & $16: 22$ & 37 & 18 & $16: 37$ & 34 \\
\hline 4 & $16: 23$ & 37 & 19 & $16: 38$ & 34 \\
\hline 5 & $16: 24$ & 37 & 20 & $16: 39$ & 34 \\
\hline 6 & $16: 25$ & 34 & 21 & $16: 40$ & 34 \\
\hline 7 & $16: 26$ & 37 & 22 & $16: 41$ & 34 \\
\hline 8 & $16: 27$ & 34 & 23 & $16: 42$ & 37 \\
\hline 9 & $16: 28$ & 34 & 24 & $16: 43$ & 34 \\
\hline 10 & $16: 29$ & 34 & 25 & $16: 44$ & 34 \\
\hline 11 & $16: 30$ & 34 & 26 & $16: 45$ & 34 \\
\hline 12 & $16: 31$ & 34 & 27 & $16: 46$ & 37 \\
\hline 13 & $16: 32$ & 32 & 28 & $16: 47$ & 34 \\
\hline 14 & $16: 33$ & 34 & 29 & $16: 48$ & 37 \\
\hline 15 & $16: 34$ & 34 & 30 & $16: 49$ & 34 \\
\hline
\end{tabular}

Sumber: [Hasil dan Pembahasan]

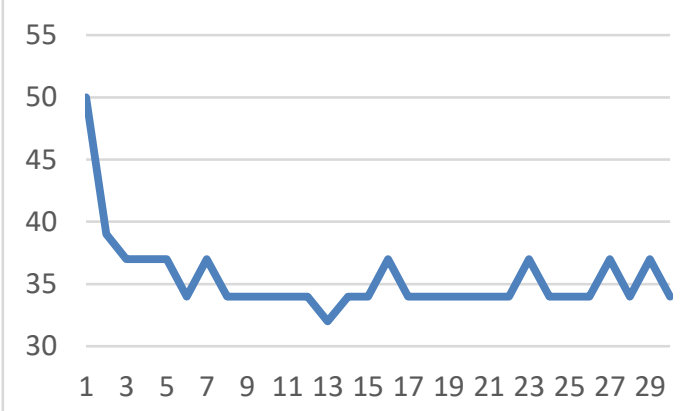

Gambar 8. Grafik Kadar Gas CO

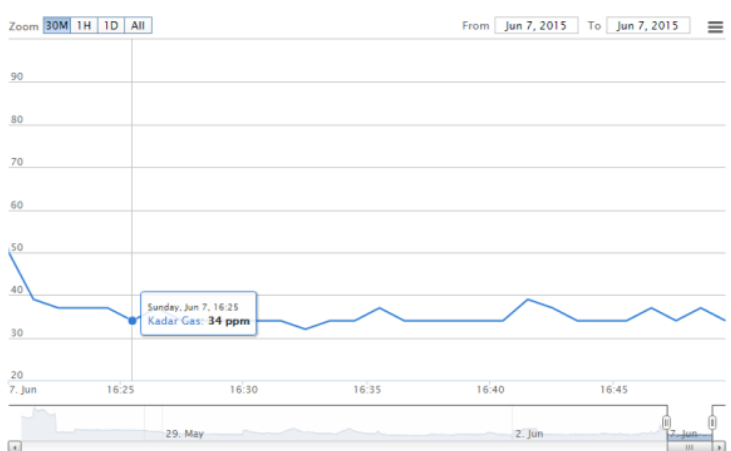

Gambar 9. Hasil Visualisasi Live Monitoring

Kedua grafik pada Gambar 8 dan Gambar 9 terlihat memiliki pola yang identik sama. Berdasarkan hal tersebut dapat disimpulkan bahwa informasi yang disampaikan pada antarmuka web sama dengan data yang dikirimkan oleh Raspberry Pi. 
Dari Tabel 4 juga akan dicari nilai kadar gas CO tertinggi dan terendah sehingga dapat dilakukan perbandingan hasil dengan antarmuka web dalam sistem visualisasi record monitoring. Berikut merupakan grafik kadar tertinggi dan terendah berdasarkan pada Tabel 4.

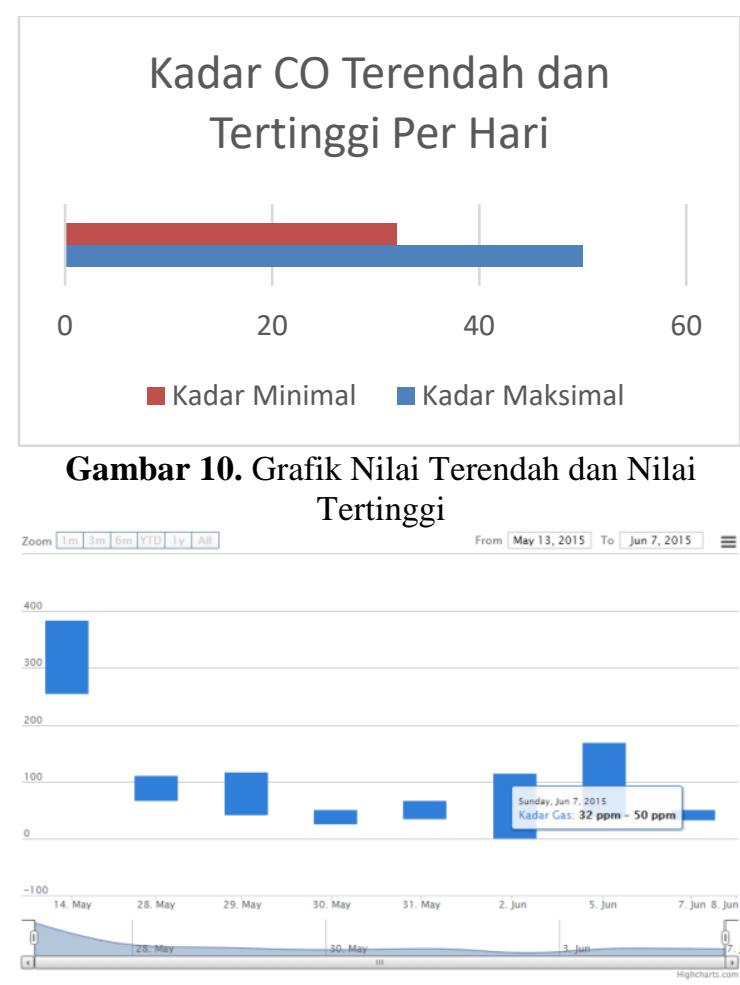

Gambar 11. Hasil Visualisasi Record Monitoring

Dari Gambar 10 dan Gambar 11 terlihat bahwa sistem visualisasi record monitoring dapat menampilkan nilai terendah dan nilai tertinggi secara akurat sehingga dapat diambil kesimpulan bahwa sistem visualisasi data sudah dapat memenuhi kebutuhan fungsionalitas yang telah dirancang.

\section{KESIMPULAN DAN SARAN}

\section{Kesimpulan}

Berdasarkan hasil perancangan dan pengujian, untuk sistem monitoring gas karbon monoksida (CO) menggunakan embedded system raspberry pi dan sensor MQ-7, dapat diambil kesimpulan berikut ini:

1. Dengan sensor MQ-7 dan Raspberry Pi yang dihubungkan melalui jalur komunikasi I2C dapat dimanfaatkan sebagai sistem yang mampu meng-capture kadar gas $\mathrm{CO}$ sebagai bagian dari sistem monitoring.

2. Dengan menggunakan Raspberry Pi yang terhubung dengan internet melalui media GPRS modem dapat dimanfaatkan untuk mengirimkan data kadar gas $\mathrm{CO}$ dalam sistem monitoring.
3. Dengan menggunakan VPN, maka Raspberry $\mathrm{Pi}$ yang terhubung dengan internet melalui media GPRS modem dapat memiliki static IP yang berfungsi sebagai identitas pengirim data kadar gas $\mathrm{CO}$ dalam sistem monitoring. Selain itu, dengan adanya static IP juga dapat memaksimalkan kemampuan Raspberry Pi sehingga dapat dilakukan remote access dari jarak jauh.

4. Dengan menggunakan web server yang terintegrasi dengan database yang menyimpan data kadar gas CO dapat dimanfaatkan untuk menampilkan data kadar gas $\mathrm{CO}$ dalam bentuk grafik pada sistem monitoring.

\section{Saran}

Sistem monitoring gas karbon monoksida (CO) ini masih memiliki beberapa kekurangan. Terkait hal ini, saran untuk penelitian selanjutnya adalah:

1. Penggunaan alat pembanding dalam melakukan kalibrasi sensor, sehingga didapatkan hasil deteksi yang lebih akurat.

2. Sistem dapat ditambahkan fungsi autoconnect maupun auto-reconnect apabila terputus dari jaringan yang menggunakan teknologi GPRS modem.

\section{DAFTAR PUSTAKA}

[1] Ohara, Gheyb Jhuana. 2005. "Aplikasi Sistem Monitoring Berbasis Web Untuk Open Cluster". Sekolah Tinggi Telkom Bandung.

[2] Partner, Kevin. 2014. "Ultimate Guide to Raspberry Pi 2". London: Dennis Publishing Ltd.

[3] S, Bhuvaneswari and Sahaya Anselin Nisha. 2014. "Implementation of TCP/IP on Embedded Webserver Using Raspberry Pi In Industrial Application". International Journal of Advanced Research in Computer and Communication Engineering Vol. 3.

[4] Sibaranin, Marimbun. 2008. "Implementasi Sistem Wireless Sensor Network Berbasis Internet Protocol (IP) Untuk Pemantauan Tingkat Polusi Udara”. Universitas Indonesia Depok.

[5] Slamet. 2005. "Sistem Monitoring Sumber Daya Hardware Berbasis Web Untuk Public Cluster LIPI". Universitas Indonesia Depok.

[6] Xenakis, Christos and Lazaros Merakos. 2002. "On Demand Network-wide VPN Deployment in GPRS”. 